\title{
Aspectos sociocognitivos do fracasso escolar
}

Rita Ribeiro Voss

Universidade Federal de Pernambuco

\section{Resumo}

As estatísticas governamentais sobre o ensino básico correlacionam origem social e fraco desempenho escolar. Quatro concepções marcam as pesquisas sobre o tema, que são insuficientes para compreendê-lo em sua complexidade: "concepção social", "concepção psicológica", "concepção microestrutural" e "concepção pedagógica". Numa perspectiva interdisciplinar, os bens simbólicos medeiam processos cognitivos e meio social. Mas a sociedade transforma esse acesso em habilidade de se fazer abstrações. Para as crianças das classes populares, esse processo se dá, sobretudo, na escola, que obstrui o fluxo livre desses bens, tornando-se o lócus de "sonegação de saberes" e principal promotora de desigualdades sociais no Brasil.

Palavras-chave: Fracasso escolar. Cognição. Sociedade.

\section{Sociocognitive aspects of scholar failure}

\section{Abstract}

The government's statistics on basic education correlation social origin and poor school performance. Four conceptions determine the research on the subject, which is not enough to understand it in its complexity: "social conception", "psychological conception", "microstructural conception" and "instructional conception". In the interdisciplinary perspective, the symbolic goods mediate the cognitive processes and social environment. However, the society transforms such access in ability to make abstractions. For the children from the popular classes, this process takes place mainly in the school that obstructs the free flow of the symbolic goods, becoming the locus of "evasion of knowledge" and the main promoter of social inequalities in Brazil.

Keywords: School failure. Cognition. Society. 
Aspectos sociocognitivos do fracasso escolar

\section{Aspectos sociocognitivos del fracaso escolar}

\section{Resumen}

Las estadísticas del gobierno en materia de educación básica correlacionan origen social y bajo rendimiento escolar. Cuatro concepciones marcan la investigación sobre el tema, que no son suficientes para entenderlo en su complejidad: " concepción social", "concepción psicológica", " concepción microestructural "y " concepción de instrucción". En una perspectiva interdisciplinaria, los bienes simbólicos median los procesos cognitivos y el medio social. Pero, la sociedad convierte ese acceso en capacidad de hacer abstracciones. Para los niños de las clases populares este proceso ocurre, principalmente, en la escuela, que obstruye el libre flujo de estos bienes, convirtiéndose en el lugar de "retención de saberes" y la principal promotora de las desigualdades sociales en Brasil.

Palabras-clave: Fracaso Escolar. Cognición. Sociedad.

\section{Introdução}

Várias pesquisas corroboram a ideia de que o fracasso escolar é uma condição crônica da educação brasileira, principalmente no que diz respeito à escola pública. As pesquisas do Instituto Nacional de Estudos e Pesquisas Educacionais Anísio Teixeira (Inep) mostram um quadro muito desfavorável ao desempenho escolar de crianças e jovens do ensino básico público. Graças à adoção do Índice de Desenvolvimento da Educação Básica (ldeb), conhecemos com mais precisão o fosso aberto entre a classe média e as classes populares, estas usuárias do sistema público de educação.

Um olhar para o Sistema de Avaliação da Educação Básica (Saeb), que avalia o ensino básico, permite identificar problemas que emergem do modelo educacional brasileiro que perpetua as desigualdades sociais e que influenciam os processos cognitivos, cujo resultado é avaliado como fracasso ou sucesso escolar.

Em termos da reflexão proposta sobre a relação entre desigualdades sociocognitivas e fracasso escolar, o artigo, num primeiro momento, procura o sentido que subjaz nos pressupostos que norteiam os testes de avaliação para medir as habilidades cognitivas de crianças e jovens, estudantes do ensino 
básico das escolas públicas brasileiras. Em seguida, recuperamos algumas concepç̃oes que respaldam o estudo do fenômeno fracasso escolar, considerando - desenvolvimento das pesquisas sobre o tema. A problemática nos dirige a pensar a aprendizagem numa perspectiva interdisciplinar, considerando cognição e sociedade cuja interação se dá por meio de bens simbólicos, isto é, estes são adquiridos socialmente. Essas interações simbólicas e seu fluxo na escola esclarece como as desigualdades sociais se transformam em condição desfavorável para o desenvolvimento de habilidades cognitivas.

\section{O quadro: pressupostos da avaliação educacional}

O Saeb testa proficiência em leitura e matemática do ensino básico para averiguar as competências desenvolvidas e habilidades adquiridas pelos alunos de ensino básico no Brasil. Pela natureza quantitativa dessas pesquisas, a análise fica muito aquém das implicações da avaliação associada às disparidades dos contextos sociais, econômicos, culturais e regionais em que elas são realizadas. Apenas, indicam, com os seus dados, problemas sociais que produzem efeitos educacionais relativos à aprendizagem. Como faltam estudos qualitativos, interpretativos, não é possível, com base, apenas, nesses instrumentos, produzir políticas públicas para o que chamamos de democracia cognitiva, possibilitando o acesso de alunos das classes populares a bens simbólicos: meios necessários para desenvolvimento de habilidades cognitivas. Nessa situação, nos defrontamos com o problema de saber se apenas os esforços de alunos, professores e diretores são suficientes para gerar os resultados que esperam os envolvidos na educação, a sociedade, o Estado, a família e a escola, uma vez que o acesso a bens simbólicos sustenta o desempenho escolar, que, por sua vez, é, também, uma fronteira social, marcos de desigualdades sociais.

Apesar dessa limitação, os dados do Saeb são claros. Com a criação e adoção, em 2001 do ldeb, o acesso a informações importantes sobre o desempenho escolar melhorou, consideravelmente, o que nos permite avaliar, de forma mais segura, o quadro geral da educação básica brasileira. Em termos de diagnóstico, o índice se mostrou eficiente. Analfabetismo, reprovação, evasão escolar são maiores e o desempenho escolar é menor nas regiões Norte e Nordeste. E, no geral, é melhor o desempenho de alunos de escolas particulares do que das públicas. Esses dados indicam uma relação de dependência 
Aspectos sociocognitivos do fracasso escolar

entre desenvolvimento regional, condição financeira e desempenho escolar, ainda em condição de exclusão da maioria dos estudantes brasileiros, em que, aparentemente, a condição de classe é uma variável importante a considerar, conforme dados do Saeb 2005.

No entanto, o instrumento não é eficaz, por força mesmo de ser um índice, quando se trata de avaliar, criticamente, os próprios pressupostos com os quais se organiza um sistema educacional excludente. Esses pressupostos se encontram nas matrizes de referência do Saeb explicitadas no "PDE: Plano de Desenvolvimento da Educação - Saeb: ensino médio: matrizes de referência, tópicos e descritores", publicado pelo Inep em 2008 que referencia as avaliações do Saeb.

Em 2001, as matrizes referenciais foram atualizadas segundo o documento dos Parâmetros Curriculares Nacionais (PCN). Essa atualização foi amparada por consultas feitas a, aproximadamente, 500 professores em doze estados da federação "com o objetivo de comparar as Matrizes de Referência existentes e o currículo utilizado pelos sistemas estaduais com os PCNs" (BRASIL, 2008 , p. 10). A atualização emergiu, então, da comparação das matrizes de referências anteriores com os currículos na época em vigor. Nota-se que não 168 está claro se os currículos atendiam às mudanças na própria concepção de educação dadas as demandas da sociedade contemporânea previstas nas Leis de Diretrizes e Bases (LDB). O que se intentou, na verdade, foi avaliar os resultados do existente, de um sistema educacional amplamente criticado em função do distanciamento entre os PCNs e a realidade escolar num país de grandes diferenças sociais, econômicas, culturais e regionais e de desigualdades enraizadas em sua história.

$\bigcirc$ próprio documento reconhece suas fragilidades com relação à adoção de uma política educacional de resultados e por considerar as competências de forma superficial (PDE, 2008). $\bigcirc$ que aparece com mais força, no entanto, é a carência de uma reflexão mais profunda sobre o enfrentamento à secular desigualdade social que reveste as chamadas competências e habilidades. Para se considerar as habilidades cognitivas adquiridas no processo educacional, é preciso, também levar em conta a desigualdade social que permeia o sistema educacional brasileiro; na desigual apropriação de bens simbólicos, meios necessários para desenvolver as habilidades cognitivas. 
Para compreender a relação entre habilidades cognitivas e apropriação desigual de bens simbólicos, é preciso adotar uma forma de pensar que conecte noções aparentemente não relacionadas, isto é, cognição humana tida como um processo que acontece, apenas, no cérebro, quando se assume um ponto de vista reducionista -, e interação simbólica, que se dá em meio às relações de sociabilidade, no ambiente mais imediato onde o aluno vive e atua socialmente. Ao adotar essa perspectiva, percebe-se, criticamente, os pressupostos que embasam os instrumentos de avaliação do ensino básico.

documento "SAEB 2001: Novas Perspectivas" (2002) define competência como "[...] capacidade de agir eficazmente em um determinado tipo de situação, apoiando-se em conhecimentos, mas sem se limitar a eles" (PERRENOUD, 1993 apud BRASIL, 2002, p. 1 1). Nessa perspectiva, trata-se de mobilizar os conhecimentos adquiridos na escola.

Assim, as competências cognitivas podem ser entendidas como as diferentes modalidades estruturais da inteligência que compreendem determinadas operações que o sujeito utiliza para estabelecer relações com e entre os objetos físicos, conceitos, situações, fenômenos e pessoas (BRASIL, 2008, p. 18).

Obviamente, o conhecimento deve operar visando mostrar os nexos entre conceitos e realidade. A diferença, no entanto, está em considerar fenomenologicamente a experiência do sujeito no mundo na escola e tornar currículos e didáticas adequados. Daí uma disparidade, as políticas educacionais não consideram o entorno, a realidade mais imediata em que o aluno está inserido - comunidade, escola, família - e as sociabilidades, acionadores cognitivos de um processo dinâmico de produção da vida social, uma vez que a organização escolar, predominantemente o currículo, é prescritiva, nos termos em que Goodson (2007) entende os processos de exclusão educacional.

Ao contrário, os instrumentos de avaliação consolidam a ideia de que o estudante precisa apreender um conjunto de abstrações no interior de um currículo idealizado para crianças e jovens no topo da hierarquia social que entram nas séries iniciais em vantagem cognitiva em relação às crianças de escola pública, pois seu ambiente de origem naturaliza operações cognitivas abstratas facilitadas pelo acesso a bens simbólicos e pela troca semântica. Segundo Bernstein (2003), ao se referir ao currículo, há um código "restrito", contextualizado, colado ao cotidiano, com o qual as crianças e jovens da base 
da pirâmide social estão mais habituados e um "elaborado" de característica universal, altamente abstrato. E, essa lógica que privilegia as abstrações, reproduzindo, assim, as condições excludentes da educação na escola.

Essa condição cognitiva se reflete nos testes, nas avaliações, aos quais os estudantes são submetidos e ficam mais evidentes nas pesquisas que visam compreender as estatísticas da educação excludente no Brasil. Carlos Henrique Araújo e Nildo Lúzio (2005) avaliam os resultados dos investimentos do Estado no ensino fundamental e médio no país entre 1991 e 2004 analisando o desempenho dos alunos. Os resultados indicaram alguns avanços como maior acesso da população em geral à educação em todos os níveis. Entre os incentivos a esse acesso está o Programa Bolsa Família, criado em 2003, que atrelou o benefício à matrícula das crianças na escola. Outro avanço foi a queda do analfabetismo.

No entanto, o desempenho dos alunos, nos testes de proficiência das habilidades adquiridas, revelou-se crítico. Com relação à leitura, Araújo e Lúzio (2005, p. 43) afirmam, "[...]a análise dos resultados de desempenho em Leitura mostra que, de maneira geral, as médias do Brasil estão abaixo do que seria aceitável; a mesma conclusão se aplica às Regiões e aos Estados". 170 Isso significa dizer que a inserção social dos alunos dos mais variados contextos regionais e nacionais fica comprometida por não haver desenvolvido uma habilidade leitora. Em matemática, os autores constatam um desempenho muito aquém do razoável e que os alunos precisam ser "[...] incentivados a resolver um significativo número de problemas, sempre raciocinando sobre situações do cotidiano" (ARAÚJO; LÚZIO, 2005, p. 49). Os pesquisadores concluíram que há uma grande distância entre o que os currículos e seus conteúdos efetivam como aprendizado necessário e o letramento como habilidade leitora no domínio do cotidiano.

Segundo Bonamino, Coscarelli e Franco, os estudantes brasileiros não operam no sentido de associar e organizar as várias disciplinas que possam auxiliá-los a resolver problemas de ordem pragmática. "É preciso que ele lo aluno) seja capaz de fazer as inferências que o texto exige e relacioná-lo a outras áreas do conhecimento, reforçando o conceito da interdisciplinaridade" (BONAMINO; COSCARELLI; FRANCO, 2002 p. 11 1). Portanto, a avaliação do sistema educacional deve ser também reflexiva, para identificar mudanças necessárias na própria concepção de educação para atender às demandas da sociedade contemporânea, que requerem um pensamento contextualizado 
capaz de identificar soluções de problemas que emergem da realidade, seja ela no trabalho ou na vida pessoal.

Por falta de uma perspectiva qualitativa das políticas educacionais brasileiras, as carências do sistema educacional são percebidas como problemas de recepção de currículos, de modelos de aprendizagem nas escolas concebidos de cima para baixo. É fato que esforços isolados, muitas vezes, mostram os resultados esperados pelo Ministério da Educação e Cultura - MEC - mesmo enfrentando muitas adversidades, quando sem recurso algum, professores e diretores, por força da vontade, conseguem alterar a condição de crianças em condições precárias em uma determinada escola. No entanto, não se pode esperar atos heroicos para a resolução de problemas educacionais, mas políticas que possibilitem reverter a situação do desempenho escolar para além de resultados e de metas a serem burocraticamente alcançados. Estes, embora tenham o mérito de retornar à população as políticas educacionais em vigor, tornando públicas as ações governamentais, deveriam também promover uma discussão sempre atualizada pelas necessidades e desafios da sociedade brasileira.

Em síntese, as desigualdades que divisam os desempenhos escolares na educação brasileira não são apenas sociais porque elas produzem efeitos cognitivos. Isso quer dizer que é preciso esclarecer a condição sociocognitiva da aprendizagem humana que as pesquisas não revelam, tornando mutilados os conceitos que tratam do desempenho escolar.

\section{Concepções de fracasso escolar}

A palavra fracasso significa falhar, ter mau êxito, em algum empreendimento. A palavra, no âmbito escolar, serve para classificar o aluno que não atende à expectativa de aprendizagem de professores, pais, dirigentes escolares e/ou sistemas governamentais de avaliação. O significado de fracasso é, então, socialmente construído em razão das expectativas gerais da sociedade.

sucesso depende do sentido da palavra que o complementa o fracasso porque é medido pela expectativa de que os alunos através da educação possam atender aos interesses pessoais e da sociedade, visando, assim, reproduzir e consolidar suas práticas, valores, costumes e também a hierarquia social. Na maioria das vezes, ter sucesso significa se apropriar de um universo 
simbólico muito antes da vida escolar. A origem familiar e social, - embora não se possa reduzir o problema aqui abordado a essa dimensão -, exerce papel importante no fraco desempenho escolar, não por coincidência ou acaso, de alunos da rede pública de ensino no Brasil. Essa realidade que se diferencia da escola privada, diz, de antemão, quem irá, no futuro, ocupar os cargos decisórios e receber os melhores salários. Esse processo "seletivo", embora pareça ser meritório, na verdade, é arbitrário e injusto, uma vez que os alunos envolvidos nesse processo não partem das mesmas condições e oportunidades daqueles que já operam com destreza os instrumentos cognitivos desenvolvidos desde a mais tenra infância.

Sucesso e fracasso são, pois, dois aspectos de um mesmo fenômeno que naturalizam sentidos sociais arbitrários. Mas insistimos, apesar dessa arbitrariedade, é assim que a sociedade seleciona os "melhores" segundo critérios bem definidos para o "preenchimento" de postos condizentes com a hierarquia social. A naturalização dessas posições está fortemente respaldada em condições "inatas" que capacitariam mais alguns alunos do que outros a aprender. É verdade que fracasso e sucesso escolares só podem ser expressos por um indivíduo, ainda que as habilidades cognitivas sejam adquiridas socialmente, o que 172 mascara o fracasso como questão individual, apartada que estão dos vínculos sociais. Por essa razão, muitas vezes, é o próprio fracasso escolar que é negado enquanto fenômeno social (CHARLOT, 2000; 201 1). Mas, examinando as relações entre indivíduo e sociedade, a percepção pessoal do fracasso e do sucesso só pode ser compreendida, apreendida, como produção coletiva, produto de interação simbólica, ainda que o indivíduo a justifique atribuindo seu desempenho a condições interiores inatas, como dom e inteligência. Portanto, fracasso e sucesso são construções sociais percebidas individualmente, num processo de enculturação que as naturalizam. Daí a dificuldade dos pressupostos que norteiam as pesquisas sobre desempenho escolar. $\bigcirc$ pesquisador do assunto também pode ter uma visão naturalizada do fracasso, confundindo um problema educacional com aquilo que acredita ser a natureza do problema, tornando-a pressuposto.

fracasso escolar é uma questão complexa que envolve dinâmica escolar, relação professor-aluno, sociedade, política, cultura e cognição. A relação sociedade e cognição, no que se refere ao desempenho escolar, é muito pouco abordada merecendo, assim, maior aprofundamento. Por isso, é importante privilegiar os aspectos sociocognitivos do fracasso escolar, reconhecendo 
as diversas facetas do fenômeno. $\bigcirc$ olhar interdisciplinar, que constitui a perspectiva desse artigo, reconhece a necessidade de recorrer às instâncias separadas nas análises mas que, ao contrário, são inseparáveis enquanto processo que resulta em conhecimento.

A apreensão do conhecimento na sociedade brasileira se dá de forma desigual, quando consideramos a hierarquia social e suas regras distributivas de bens simbólicos. Por sua vez, a sociedade constrói vias de acesso do sujeito ao universo simbólico acumulado por ela. Acesso e acumulação individual conferem ao estudante um cabedal para o futuro que ele deverá manipular na vida pessoal, social e profissional. A relação sociedade e indivíduo na aprendizagem dá a medida de sua importância no desenvolvimento do capital intelectual e das habilidades cognitivas. Isso quer dizer que o entendimento do desempenho escolar é indissociável da compreensão dos processos cognitivos e das condições sociais de acesso a bens simbólicos.

Essa associação, no entanto, fica obscurecida quando se consulta a bibliografia a respeito do assunto. Identificam-se quatro concepções de fracasso escolar nas pesquisas e estudos pedagógicos no Brasil: a "concepção social", cuja responsabilidade pelo fracasso recai nas condições socioeconômicas desfavoráveis aos alunos das classes populares que reproduzem as condições de desigualdade na sociedade; a "concepção psicológica" que explica o fracasso como drama individual, uma condição intelectual desfavorável para a aprendizagem, reduzindo assim a questão a problemas psicológicos; a "concepção microestrutural" identificando as razões do fraco desempenho escolar na própria estrutura da escola; e, por fim, a "concepção pedagógica", que, embora identifique a relação professor e aluno na apreensão de saberes, o fracasso está centrado na dificuldade deste último em se mobilizar interiormente para aprender.

Segundo Angelucci, Kalmus, Paparelli e Patto (2004), os recortes de pesquisa sobre o desempenho escolar, configuraram, historicamente, a pesquisa educacional no Brasil. A criação do Inep, em 1938, foi fortemente influenciada pela Escola Nova. Há nessas pesquisas inaugurais da instituição presença marcante de estudos da psicologia sobre ensino e aprendizagem e sobre instrumentos de avaliação psicopedagógicos. A psicologia do fracasso escolar tornou-se não apenas uma tendência forte no período como também consolidou algumas concepções sobre o fenômeno que alicerçam e, ao mesmo tempo, conduzem, as pesquisas, até hoje, de forma velada ou explícita. 
Aspectos sociocognitivos do fracasso escolar

Os temas de pesquisa realizadas na Universidade de São Paulo entre (1991-2002), elencados por Angelucci, Kalmus, Paparelli e Patto confirmam tal afirmação. "Distúrbio do desenvolvimento e problemas de aprendizagem", "Remediação do fracasso escolar" e "Papel do professor na eliminação do fracasso escolar" não deixam dúvida de que, nessa "concepção psicológica", o problema escolar recai no aluno, cujo desempenho, muitas vezes, é atribuído à inteligência e imaturidade emocional. Por vezes, o problema reside nos professores, quando o fracasso do aluno é atribuído às habilidades técnicas do docente e, daí, a explicação de suas deficiências num nível psicológico. Isto é, ainda que a "culpa" seja do professor, é, em última análise, um problema cognitivo. Os autores observam que, nessa linha analítica, está explícita uma intenção normativa segundo a qual tanto as dificuldades emocionais como as carências culturais devem ser resolvidas com técnicas adequadas. $\bigcirc$ fracasso escolar, então, nessa concepção é tomado como desvio da média; aluno lou mesmo o professor) não se encontra em condições "normais" em que a aprendizagem é bem-sucedida.

Nos anos de 1980, no polo oposto à "concepção psicológica" as pesquisas procuraram compreender as condições sociais, econômicas, culturais 174 e políticas do fracasso escolar, na perspectiva da análise crítica, herdeira da teoria marxista, presente, principalmente, nas teorias de Althusser, Bourdieu e Gramsci. Nessa perspectiva crítica, as pesquisas concluem que o sistema educacional brasileiro atende a uma lógica excludente, com desigualdades sociais que o transversalizam. Mas, embora as pesquisas tenham o mérito de inserir as condições externas aos sujeitos, para compreender o desempenho escolar, há uma "compreensão parcial", a partir de uma exclusiva "concepção social" dos problemas educacionais:

[...] ao mesmo tempo em que afirmam que para pensar a escola e seus resultados, é preciso tomá-la como instituição seletiva e excludente, retomam o tecnicismo ao admitirem a possibilidade de por sob controle o fracasso escolar por meio da adequada implementação de políticas educacionais "progressistas", com especial ênfase na política de ciclos de aprendizagem. $\bigcirc$ insucesso de reformas e projetos nesta direção encontra explicação no conservadorismo dos professores que, pela resistência à inovação, prejudicam a sua implementação. A saída apontada é o investimento na formação intensiva de professores, de modo a levá-los a conhecer em profundidade as propostas governamentais e, assim, garantir a realização do objetivo final de reformas e projetos oficiais: a reversão 
do fracasso escolar (ANGELUCCl; KALMUS; PAPARELLI; PATTO, 2004, p. 62).

As duas concepções enunciadas polarizam o problema e impedem o esclarecimento do que apontam as estatísticas governamentais, principalmente nas escolas públicas, como o alto índice de evasão, de repetência, faltas, além de aspectos cognitivos, que configuram a situação vivida por milhões de estudantes no país. Nesse sentido, Arroyo critica o que ele chama de consolidação de uma cultura do fracasso escolar, cujas análises tradicionalmente não consideram as relações cotidianas na escola:

É curiosamente triste constatar que o pensamento educacional brasileiro, até o mais progressista, não dá o devido destaque a esses componentes materiais, estruturais do processo educativo. Preferiu centrar-se durante décadas nas capacidades dos discentes, no preparo dos docentes, nos conteúdos transmitidos e nos métodos de transmissão. É curiosamente triste porque, em contextos onde esses componentes materiais poderiam ser menos determinantes, eles têm sido tratados como a centralidade que merecem. Referimo-nos às reformas educacionais dos sistemas escolares dos países onde o fracasso escolar é bem menos gritante do que entre nós. Nas três últimas décadas, passou-se de uma atribuição do fracasso à diversidade dos alunos e das famílias, e às diferenças na cultura, para a diversidade das escolas, sua cultura e sua organização (ARROYO, 1992, p. 47).

Arroyo pertence à corrente que, no final dos anos 80, começa a pensar o cotidiano escolar, adotando uma "concepção microestrutural" do desempenho escolar influenciada pela sociologia do cotidiano de Agnes Heller. Dessa forma, o fracasso é entendido no interior da estrutura de poder na cultura escolar. Nessa perspectiva, Patto (1988) propõe a averiguação das afirmações da corrente "crítica", isto é, se as dificuldades que levam as crianças pobres ao fracasso se encontram reproduzidas na sala de aula:

[... ] se a escola pública é adequada às crianças de classe média, se o professor tende a agir, em sala de aula, tendo em mente um aluno ideal e se os professores não entendem e discriminam seus alunos de classe baixa por terem pouca sensibilidade e grande falta de conhecimento a respeito dos padrões culturais dos alunos pobres, em função de sua condição de classe média, como afirmam as versões de fracasso escolar atualmente em vigor (PATTO, 1988, p. 77). 
Segundo Angelucci (2004), essa é a tendência das pesquisas contemporâneas, olhar mais próximo para a escola considerando a dinâmica e construção de sociabilidades em seu interior. Assim, as hipóteses ligadas ao fracasso escolar podem ser 'averiguadas'; e alunos e professores não são tomados como ficções "seres tão imaginários quanto aqueles a que se referem expressões como 'homos economicus', 'aluno médio', 'sujeito epistêmico' e outras semelhantes" (AZANHA apud ANGELUCCl; ANGELUCCl; KALMUS; PAPARELLI; PATTO, 2004, p. 64).

Mas, embora, seja preciso mesmo olhar para as microestruturas e como os elementos de sua organização e cultura se articulam e tornam eficazes a reprodução de uma situação extremamente desigual entre os que estão na base e no topo da hierarquia social, essa concepção não permite vislumbrar os aspectos mais gerais de um processo de "sonegação de saberes" que as estatísticas do Inep não mostram, mas que estão implícitas no jogo seletivo do sistema educacional brasileiro.

É necessário mencionar, ainda, em meio a essas discussões a "concepção pedagógica", representada por Bernard Charlot (2000), que se diferencia das demais por negar, de um lado, a existência do fracasso escolar enquanto 176 objeto de pesquisa e, de outro, afirmar a "dificuldade do aluno" em aprender, como explicação do desempenho escolar das escolas públicas brasileiras. De fato, não existe "fracasso escolar" no sentido da existência de um ente exterior ao aluno que o possui, como foi salientado anteriormente. Fracasso e sucesso escolar são construções abstratas, no sentido weberiano, são tipos ideais, modelos construídos idealmente com propósito acadêmico-científico; são guias para as nossas pesquisas, que, obviamente, buscam na realidade seus elementos constitutivos. Em torno dessas construções, os pesquisadores pretendem elucidar, esclarecer, compreender e explicar a problemática do desempenho escolar.

No entanto, é preciso reconhecer uma ponte relacional professor-aluno frente ao saber, que está na base de toda e qualquer aprendizagem formal, que o educador francês realça. Mas o processo é complexo e muito amplo, envolvendo várias dimensões e não apenas a dificuldade individual em compreender reduzindo assim o problema a uma causalidade estrita estudar-aprender, abstraído do contexto em que a aprendizagem acontece. 
Embora o autor diga que é inegável a correlação entre fraco desempenho escolar e origem social, ele convoca pesquisadores, principalmente os sociólogos, a explicar por que há alunos bem-sucedidos, que passam no vestibular provenientes das classes populares (CHARLOT, 201 1). Embora a questão seja relevante, uma das finalidades da pesquisa educacional no Brasil é explicar a relação entre o aprender (condições subjetivas) e a condição social (o contexto em que a criança aprende). Além disso, o desafio que se impõe aos pesquisadores de várias áreas do conhecimento envolvidos na educação é tornar inteligíveis os fenômenos concernentes às médias sociais, não as condições individuais do fracasso, nem os esforços isolados, embora sejam admiráveis. Ademais, o ser humano tem capacidades latentes que são mobilizadas para desenvolver habilidades cognitivas em que, embora pesem questões subjetivas, que não são todas iguais, todos fazem uso dos mesmos aparatos cerebrais, sem exceção. Daí, a questão inversa: Por que, mesmo dadas as mesmas condições cognitivas, estruturais cerebrais, a grande maioria das crianças e jovens das classes populares têm dificuldade de aprender? Essa pergunta denuncia o caráter seletivo e desigual na distribuição de saberes.

A subtração das relações sociais dificulta o entendimento das condições de desenvolvimento de qualidades subjetivas implicadas no fracasso escolar. A cognição, por ser um sistema aberto, interage com o meio porque se alimentando simbolicamente nas trocas sociais. A condição sine qua non da educação é, pois, a interação social, sem a qual nenhuma aprendizagem é possível. Não existe um ser humano que aprenda isoladamente; o sentido está justamente em ensinar a ser humano dentro de uma sociedade específica, em uma cultura particular, interagindo com os seus membros. Aprendem-se códigos, valores, modos de pensar e viver, culturalmente. Por esse aspecto sociocultural da cognição humana, na verdade, a sociedade é que fracassa ou é bem- sucedida na educação de seus membros.

Mas não se pode subestimar a "concepção pedagógica", quando se olha de maneira relacional, professor-aluno, questões epistemológicas e cognitivas importantíssimas relativas à questão da passagem de um "sujeito empírico para um sujeito epistêmico" (CHARLOT, 2011) ou como entende Maria da Conceição Almeida (2004), em como transformar a experiência individual em questões mais amplas, mais gerais, em conhecimento. Para a antropóloga, o processo cognitivo é uma espécie de "alquimia mental", uma conjunção do 
Aspectos sociocognitivos do fracasso escolar

nível, individual, coletivo, histórico em que concorrem domínios pulsionais, racionais e emocionais.

Em síntese, as quatro concepções aqui enunciadas são insuficientes para, isoladamente, compreender um processo mais complexo, embora cada uma delas problematize conceitos e tente responder ao problema em tela nos domínios disciplinares a que pertencem. $O$ que se discute e se procura inserir, neste texto, é uma perspectiva interdisciplinar, bio-socio-cultural, que, por sua natureza, não pode excluir as relações do indivíduo com a sociedade e a interação dos processos biológicos a processos culturais que configuram a aprendizagem humana.

Por fim, uma ressalva. A "concepção sociocognitiva" aqui construída é delineada numa perspectiva aberta, marcada pela incompletude da ciência e do humano. Por isso, o que há são aproximações ao assunto sustentadas pela bibliografia, pelos estudos e pelas pesquisas sobre o tema. Também não se prescindir dos estudos das concepções sobre o fracasso escolar, referidos anteriormente. Ao contrário, parafraseando Edgar Morin (2008, p. 34), integrar o problema "[...] a um conhecimento mais amplo e refletido [...]", dando-lhe "[...] um terceiro olho para enxergar o que eles não veem".

\section{Um problema de perspectiva e a concepção sociocognitiva}

Em relação à problemática discorrida em nossa revisão, procurou-se delinear uma concepção de fracasso escolar como fenômeno biocultural. De um lado, foi considerado o processo cognitivo stricto sensu, isto é um processo biológico e, de outro, o seu contexto. Ao invés de se olhar a cognição de forma disciplinar e reduzida, como processo de aprendizagem exclusivamente cerebral, ou psicológico, separadamente do universo simbólico, procurou-se considerar as capacidades cerebrais inatas associadas às condições socioculturais que resultam em habilidades cognitivas. $\bigcirc$ cérebro humano necessita do universo simbólico para o desenvolvimento dessas habilidades, como sistema aberto requer elementos do meio exterior que interagem com a organização interior do sistema cognitivo (MORIN, 2008), que são informações, codificações simbólicas, em trânsito na sociedade.

De acordo com as pesquisas mais recentes das ciências cognitivas, a relação implícita entre cognição e contexto no processo de aquisição de habilidades cognitivas não se pode ser negligenciada quando se pensa em diminuir 
as distâncias entre aqueles que têm maior acesso aos bens simbólicos e aqueles que não os possuem. Por outro lado, não se trata de realçar as carências culturais, mas de salientar aspectos interativos de natureza e cultura na cognição humana, para compreender o desempenho escolar.

\section{Cognição e sociedade}

Uma forma de compreender a ligação entre sociedade e cognição é inquirir a própria sociabilidade humana:

De onde provém a organização social? Talvez não seja programada geneticamente no homem, ou nesse caso, é-o apenas parcialmente. Decorre certamente de virtualidades organizacionais do cérebro humano, mas não automaticamente: essas virtualidades só entram em ação, na relação, ou melhor, na interação com o mundo exterior (MORIN, 1998, p. 277).

A cognição humana no sentido biológico consiste em transformar algo material, físico-químico, em função cognitiva, em transformar capacidades em habilidades, isto é, as características inatas da espécie em adquiridas, em cognição propriamente dita, por meio da aprendizagem. Para adquiri-las, o homem faz uso de um sistema cerebral complexo que permite transformar o seu trabalho em ações conscientes e intencionais. Para a aquisição dessas habilidades, o cérebro conecta, através das sinapses cerebrais, várias regiões (responsáveis pela memória, percepção visual, audição, linguagem) das mais antigas - relativamente ao processo evolutivo da espécie, como o sistema límbico -, até as mais recentes, como o córtex frontal, cuja função é dotar o Homo sapiens de raciocínio estratégico, para planejar ações, isto é, trata-se da instância racional do aparato cerebral humano. Essas características cerebrais fazem emergir a consciência, algo imponderável, qualitativamente diferente da soma das partes integrantes do cérebro, revelando, assim, a singularidade do humano, o que também possibilita a emergência do que chamamos vida espiritual, mundo intelectual. No entanto, essa condição humana se configura em potencialidades vistas isoladamente, pois dependem de interação simbólica na troca de bens intangíveis entre os homens; naquilo que a sociedade valora culturalmente; e na forma particular, cultural, como as pessoas aprendem. A aprendizagem joga 
Aspectos sociocognitivos do fracasso escolar

um papel crucial nas potencialidades humanas para simbolizar, além das atividades mais elementares como andar e falar.

Os estudos das ciências cognitivas (GAZZANIGA; IVRY; MANGUN, 2002; VARELA; THOMPSON; ROSCH, 1993) revelam que a habilidade cognitiva está relacionada à experiência, ao meio. A organização do cérebro humano, entre outras, visa reter informações importantes e descartar outras menos importantes. O cérebro, é portanto, seletivo e, muitas vezes, a seleção resulta do cálculo do sujeito em avaliar os custos e benefícios do esforço cognitivo. $\bigcirc$ universo simbólico, formado cultural e socialmente, se dá em inputs e outputs de informações que capacitam o sujeito a agir em seu meio, num circuito recursivo e são naturalizadas pela habitualidade com que o homem the imputando um valor para a vida. No terreno da criatividade, os processos recorrentes da cognição humana permitem fazer novos arranjos que engendram novos saberes, técnicas e tecnologias, que beneficiam a conservação da espécie desde seus primórdios. Conservação e criação são dois aspectos inseparáveis do processo cognitivo. É preciso conservar informação ao mesmo tempo que a aprendizagem envolve criação, no sentido de Piaget (2007), partes de um processo ascendente em que um novo patamar cognitivo envolve ao 180 mesmo tempo conservação e superação do anterior.

A sociabilidade, a interação entre os homens e o que a sociedade valoriza para os seus membros, portanto, jogam um papel decisivo para a cognição, que se revela de forma particular, em suas características culturais. Geary (1999) pesquisou as diferenças interculturais na aprendizagem de matemática de alunos americanos e asiáticos. Os resultados mostraram que o desempenho depende do meio cultural, o que já havia observado Franz Boas (20 10) ao tratar das questões raciais nos testes de inteligência realizados em sua época para justificar as diferenças entre brancos e negros nos Estados Unidos. A sociedade americana, também objeto da análise de Geary, valoriza mais as atividades esportivas. As habilidades matemáticas, então, se desenvolveriam num meio cultural que as valoriza.

Isso acontece porque os processos cognitivos são, a um só tempo, biológicos, simbólicos e culturais, dependem da quantidade de informações, de bens simbólicos possíveis de armazenar e do sentido que tem para a vida individual e coletiva. Esse armazenamento tem dupla característica: refere-se a informações que o cérebro humano está apto a estocar, e a possibilidade de transformá-las em conhecimento. A primeira característica refere-se ao domínio 
do cômputo; a segunda, à aprendizagem, que seleciona, classifica e confere aplicabilidade para a vida, é qualitativa. Essas características são gerais; o cérebro do Homo sapiens opera dessa forma mas sempre num contexto. LéviStrauss (1976) verificou essa cognição básica humana nas sociedades sem escritas, onde o conhecimento está colado à experiência e, comparando às modernas, o antropólogo concluiu que estas, diferentemente daquelas ensinam a pensar por abstrações. Portanto, o que se privilegia, nas sociedades modernas, é o conhecimento abstrato. A transmissão e trânsitos dos bens simbólicos se dão nesse domínio, das abstrações. Quanto mais cedo uma criança tem acesso aos bens - culturais, intelectuais, artísticos -, quanto mais cedo operar as abstrações mais cedo ela estará apta a teorizar, abstrair, formalizar. Em suma, estará em condições de manipulálos a seu favor a sociedade.

Em relação à expectativa da sociedade, as crianças das classes populares têm um acesso tardio às operações de abstração, devido a sua origem familiar. Na corrida do desempenho nas sociedades contemporâneas, elas partem em desvantagem em relação aos alunos das escolas privadas cujos bens simbólicos estão em trânsito na família. Quando essas crianças entram na escola, já sabem operar abstrações com naturalidade.

Nesse sentido, é reforçada a ideia de que o meio social com seus bens simbólicos e valores imputados a certos tipos de conhecimento em detrimento de outros explicam um aspecto importante do desempenho escolar dos alunos brasileiros. $\bigcirc$ caráter desigual da sociedade brasileira implica que os alunos se apropriam do mundo das palavras, das imagens, dos símbolos também de maneira desigual. É importante salientar que a posição que o sujeito ocupa em seu meio enuncia uma determinada visão e perspectiva do mundo que são naturalizadas e com elas manipula o mundo imediato, operando com arsenal abstrato já contextualizado. No entanto, quando não é possível aprender matemática ou o sentido de um texto, a justificativa do próprio sujeito frustrado em seu empreendimento de conhecer é de que não tem condições intelectuais inatas, como inteligência.

Na pesquisa em andamento sobre aspectos sociocognitivos do desempenho escolar, verificou-se, em visitas a uma escola de Olinda com Ideb menor que 4, que existe sonegação de saberes quando se observa a biblioteca fechada, tablets doados aos alunos sem conteúdo; subutilização do tempo em transmitir o conhecimento com o atraso de professores e alunos para começar a aula; e, também, pela subutilização de espaços. Claramente, a escola não 
Aspectos sociocognitivos do fracasso escolar

atrai os alunos e, também, não se preocupa em diagnosticar, para além da burocracia estatística das metas escolares, como reverter a situação no domínio das condições cotidianas e particulares da escola, sendo assim, não compensa deficiências de base social; ao contrário, aprofunda o problema. As justificativas do fraco desempenho escolar recaem sobre a incapacidade dos alunos de manipular as informações recebidas.

\section{Capital cognitivo}

problema da naturalização pelos sujeitos envolvidos na aprendizagem, portanto, é um aspecto crucial na compreensão do fracasso escolar. Para compreendê-la, recorreu-se ao conceito de Habitus. Emprestamos de Maria da Graça Jacintho Setton (2002) o sentido atribuído por ela ao conceito, por abarcar os aspectos individuais e sociais do conhecimento de forma clara e suficiente para os propósitos da pesquisa. Para a autora, o habitus surge na teoria de Bourdieu:

[...] como um conceito capaz de conciliar a oposição aparente entre realidade exterior e as realidades individuais. Capaz de expressar o diálogo, a troca constante e recíproca entre o mundo objetivo e o mundo subjetivo das individualidades, habitus é então concebido como um sistema de esquemas individuais, socialmente constituído de disposições estruturadas (no social) e estruturantes (nas mentes), adquirido nas e pelas experiências práticas (em condições sociais específicas de existência), constantemente orientado para funções e ações do agir cotidiano (SETTON, 2002, p. 63).

A cognição tem duplo aspecto (VOSS, 2009): diz respeito à capacidade de aprender algo, às condições do aparato cerebral que são universais, e à condição intelectual para manipular o mundo através de um sistema simbólico, adquirido social e culturalmente, de forma particular e contextualizada. Bens simbólicos socialmente compartilhados naturalizam habilidades adquiridas individualmente e as consolidam nas práticas sociais cotidianas, formando o que chamamos de capital cognitivo. O capital cognitivo guarda, assim, aspectos complementares do biológico e do sociocultural.

A relação entre desigualdade de acesso aos bens simbólicos e desempenho escolar se manifesta na projeção de futuro. A maior apropriação de bens 
simbólicos significa maior aquisição de habilidades, maior capital cognitivo, melhor atendimento a expectativas educacionais. Consequentemente, o destino escolar e o investimento pessoal em profissionalização com vistas a uma ascensão social são percebidos de maneira também desigual. É, preciso, então, conhecer a projeção de futuro de alunos das classes populares para esclarecer o desempenho em termos de experiência, sucesso ou fracasso nas práticas escolares, segundo o nível de apropriação de bens simbólicos no meio escolar, familiar e social.

Assim o que se chama de habilidades cognitivas se revela em estreita relação com o cotidiano, em como se contextualizam as relações com o conhecimento dentro da escola com seu universo de valores sociais, culturais, coletivos. É em meio ao cotidiano e numa realidade social mais imediata que há uma triagem do conhecimento socialmente importante para as práticas e para inserção dos membros em sociedade, segundo a hierarquia social. Para Peter Berger e Thomas Luckmann, o conhecimento tem raízes sociais e inclui o conhecimento da situação do indivíduo e seus limites (BERGER; LUCKMANN, 20011 . A sociedade diz o que é importante conhecer e a maneira como o conhecimento deve ser manejado por seus membros. É no cotidiano da escola que se pode verificar como os envolvidos se mobilizam no ato de aprender e ensinar, ou melhor, se as pessoas trabalham para o livre fluxo de bens simbólicos que compõem o capital cognitivo.

Mas não é isso o que se verifica, quando se pensa no ldeb da maioria das escolas públicas. Parece inequívoca a afirmação de que a desigualdade social no Brasil é um obstáculo ao livre fluxo e apropriação de bens simbólicos na escola porque reproduz sistemas sociais de dominação por meio de sonegação simbólica, expressão que se acredita abarcar melhor, no contexto de nossa discussão, o fracasso escolar na sociedade brasileira do que "violência simbólica", conceito desenvolvido por Bourdieu (2000). Ou seja, os alunos independentemente de sua origem social devem aprender num domínio simbólico cujo conteúdo objetiva o desenvolvimento daqueles que estão no topo da hierarquia social, isso é, a consolidação de posições sociais no futuro, depende da regulação do fluxo de bens simbólicos na escola. A escola, no Brasil, é um instrumento político de seleção extremamente desigual.

O equívoco dos sistemas de avaliação como o Saeb resulta em não esclarecer fatores do desempenho escolar relacionados à polarização econômica entre ricos e pobres, encobertos e ocultos transformados em naturalizações 
Aspectos sociocognitivos do fracasso escolar

do fracasso como crença, e que se materializam em sonegação simbólica na distribuição de saberes. $\bigcirc$ poder simbólico, diz Bourdieu "[...] não reside nos 'sistemas simbólicos em forma de uma 'illocutionery force' mas se define numa relação determinada - e por meio desta - entre os que exercem o poder e os que lhe estão sujeitos, quer dizer, na própria estrutura do campo em que se produz e se reproduz a crença" (BOURDIEU, 2000, p. 15).

\section{Cognição e poder}

A dominação simbólica é mais difícil de perceber porque é intangível; diferente da dominação exercida pela apropriação de dinheiro e bens materiais. A supremacia do conhecimento na contemporaneidade representa outra feição do sistema capitalista; não aquela calcada nos aspectos físicos da mais valia da mercadoria, mas na acumulação de mais saber.

A sociedade contemporânea caracteriza-se, principalmente, pela troca de informação e conhecimento; economias, sociedade e cultura sustentam-se na revolução da tecnologia da informação que penetra em todas as esferas da atividade humana, o que requer um acesso a níveis simbólicos mais complexos. Isso incita a teoria sociológica a identificar e a caracterizar tais mudanças no contexto social onde elas ocorrem, como estão sendo moldadas e qual é o significado social em termos de acesso à produção imaterial da sociedade.

Mas ainda que a natureza do capital cognitivo seja, de fato, qualitativamente diferente do capitalismo em seu sentido econômico (GORZ, 2005), as condições biológicas, que são físicas, fazem emergir algo imaterial, o conhecimento, como resultante de processos interativos com os bens simbólicos. Os dois aspectos formam uma condição inseparável. Marta Khol de Oliveira, ao se referir às reflexões de Vygotsky sobre a relação do substrato biológico e à construção cultural no desenvolvimento humano, ressalta "[...] a forte ligação entre os processos psicológicos humanos e a inserção do indivíduo num contexto sócio-histórico específico". Segundo ainda a autora, para Vygotsky, "[...] instrumentos e símbolos construídos socialmente definem quais das inúmeras possibilidades de funcionamento cerebral serão efetivamente concretizadas ao longo do desenvolvimento e mobilizadas nas diferentes tarefas" IOLIVEIRA, 1992, p. 26). 
Em suma, as capacidades inatas para pensar, falar, representar simbolicamente o mundo são universais como condição biocultural do homem. $\bigcirc$ desenvolvimento humano necessita da sociedade e de seus bens simbólicos para constituir um domínio linguístico, uma realidade humana, cultural. Portanto, os aspectos bioculturais se inscrevem num círculo recursivo em que os bens simbólicos geram habilidades cognitivas e estas possibilitam a criação de mais bens simbólicos. A apreensão dessas habilidades passa por regulações políticas, isto é, mais saberes significa mais poder de gestão cognitiva sobre aqueles que estão no posicionamento de base na pirâmide social. A apropriação não equitativa desses bens, no que diz respeito ao sistema educacional brasileiro, resulta em desempenhos mais fracos averiguados regionalmente ou quando se considera em termos nacionais a condição socioeconômica dos alunos das classes populares.

\section{Considerações finais}

A avaliação observada nas grandes estatísticas nacionais sobre - desempenho dos alunos das escolas públicas não leva em conta a desigualdade social, uma vez que é realizada com instrumentos padronizados e universalizados, com alunos que, logo de partida, não têm as mesmas condições para viabilizar o desenvolvimento das habilidades cognitivas, segundo as expectativas dos referidos instrumentos avaliativos. Em outras palavras, fracasso escolar exprime um processo social, fortemente marcado por políticas de "sonegação de saberes", no desenvolvimento de habilidades cognitivas em condições desiguais, o que dificulta a constituição de uma democracia cognitiva de livre fluxo e distribuição simbólica no contexto da educação brasileira.

O jogo da "sonegação de saberes" tem operadores cognitivos que agem sorrateiramente. Quando se fala de educação formal, escolar, é preciso considerar como o Ocidente desenvolveu formas particulares de educar intencionalmente, com métodos e práticas racionais. Assim, a educação formal, ao longo do desenvolvimento do Ocidente, promoveu a aprendizagem por abstrações domesticando o pensamento que opera no sentido de apreender o conhecimento de certo fenômeno, descontextualizando-o. Além disso, as sociedades com alta hierarquização social distribuem o conhecimento em termos da 
Aspectos sociocognitivos do fracasso escolar

posição ocupada pelas classes com a maior ou a menor aquisição de bens simbólicos desde da infância.

A padronização das formas de ensinar imprime, de um lado, um modelo centrado em abstrações, cuja complexidade depende da familiaridade com que elas são primeiro adquiridas na família e depois desenvolvidas na escola e, de outro lado, da distribuição dos bens simbólicos, que nas sociedades ocidentais, reiteradamente mencionada nesse artigo, é desigual, depende da hegemonia cultural de quem está no topo da hierarquia social. Quando se procura compreender essa lógica excludente num nível simbólico, percebe-se, também, que o problema reside na naturalização desses modelos francamente generalizados.

No entanto, como pressuposto de que a aprendizagem depende da articulação de dimensões sociais e cognitivas, é possível se aproximar aproximar da dinâmica escolar, das relações e interações que permitem as apropriações simbólicas que resultam em desempenho escolar. Em termos pragmáticos, significa dizer que é preciso fazer fluir bens simbólicos dentro da escola, no sentido contrário da "sonegação de saberes". Essa sonegação está amalgamada às naturalizações do fracasso introjetadas não apenas por alunos e por professo186 res ao longo da vida escolar mas também pela sociedade. A crença de que crianças e jovens das classes populares têm "menos" condição cognitivas, por isso são ineptas a aprender, deve ser substituída por uma ética de compensação da escola de uma situação alheia às capacidades cognitivas. Por outro lado, não se pode olhar a escola como uma instituição constrangida apenas por forças sociais. É preciso apostar na escola como centro de saberes, numa relação genuinamente pedagógica, como a cunhada pelos gregos, de orientar e conduzir as pessoas ao conhecimento.

As estatísticas governamentais são guias, instrumentos meramente referenciais, fotografia de uma situação geral, mas, ao se tornarem um centro indicativo de obrigação de cumprimentos de metas meramente burocráticas, esbarram no fato de que a realidade escolar escapa aos padrões estabelecidos idealmente, estão inseridas numa realidade ao mesmo tempo social, cultural e política. Enfrentar o problema do fracasso escolar, que aqui se dimensiona de forma complexa é dizer que na escola se encontram as próprias condições de formação de um ambiente de aprendizagem pautado nas potencialidades da cognição humana e no reconhecimento do papel da sociedade no processo 
formativo de espaços para o conhecimento e para o comprometimento social com a educação.

\section{Referências}

ALMEIDA, Maria da Conceição. Um itinerário do pensamento de Edgar Morin. São Leopoldo, Universidade do Vale do Rio dos Sinos (UNISINOS), 14 abr. 2004. (Palestra no Ciclo de Estudos sobre 'o Método' de Edgar Morin Promovido pelo Instituto Humanitas).

ANGELUCCI, Biancha; KALMUS, Jaqueline; PAPARELLI, Renata; PATTO, Maria Helena Souza. O estado da arte da pesquisa sobre o fracasso escolar (1991-2002): um estudo introdutório. Educação e Pesquisa, São Paulo, v. 30, n. 1, p. 51-72, jan./abr. 2004.

ARAÚjO, Carlos Henrique; LUZIO, Nildo. Avaliação da Educação Básica: em busca da qualidade e equidade no Brasil. Brasília: Instituto Nacional de Estudos e Pesquisas Educacionais Anísio Teixeira, 2005.

ARROYO, Miguel. Fracasso-sucesso: o peso da cultura escolar e do ordenamento da educação básica. Em Aberto, Brasília, v. 11, n. 53, p. 46-53, jan./mar. 1992.

BERGER, Peter; LUCKMANN, Thomas. A construção social da realidade: tratado de sociologia do conhecimento. 20. ed. Tradução Floriano de Souza Fernandes. Petrópolis: Vozes, 2001.

BERNSTEIN, Basil. Class, codes and control. London: Routledge, 2003.

Class and pedagogies: visible and invisible. London: Routledge, 1975.

BOAS, Franz. Antropologia cultural. 6. ed. Tradução Celso Castro. Rio de Janeiro: Zahar, 2010.

BONAMINO, Alícia; COSCARELLI, Carla; FRANCO, Creso. Avaliação e letramento: concepções do aluno letrado subjacente ao SAEB e ao PISA. Educação \& Sociedade, Campinas, v. 23, n. 81, p. 91-113, dez. 2002. Disponível em: <http://www.cedes.unicamp.br>. Acesso em: 20 out. 2009.

BOURDIEU, Pierre. O poder simbólico. 12. ed. Tradução Fernando Tomaz. Rio de Janeiro: Bertrand Brasil, 2000.

BRASIL. SAEB. Novas perspectivas. Brasília: Instituto Nacional de Estudos e Pesquisas Educacionais, 2001. 
Primeiros resultados: médias de desempenho do SAEB/2005 em perspectiva comparada fevereiro de 2007. Disponível em: <http://www.afrobras.org.br/pesquisas/ saeb2005.pdf> Acesso em: 20 out. 2009.

PDE/SAEB. Plano de Desenvolvimento da Educação. SAEB: ensino médio: matrizes de referência, tópicos e descritores. Brasília: MEC/Inep, 2008.

CHARLOT, Bernard. Da relação com o saber. Tradução Bruno Magne. Porto Alegre: Artmed, 2000 .

Existe fracasso escolar? Entrevista. UNIVESP TV. Brasil, 2011 . 13:36 min. Disponível em: <http://univesptv.cmais.com.br/bernard-charlotexiste-o-fracasso-escolar>. Acesso em: mar. 2014.

GAZZANIGA, Michel; IVRY, Richard; MANGUN, George. Ron. Cognitive Neuroscience: the biology of the mind. 2. ed. New York: W. W. Norton \& Co., 2002.

GEARY, David. Biology, culture and cross-national differences in mathematical ability. In: STEMBERG, Robert; BEN-ZEEVE, Talia (Org.). The nature of mathematical thinking Malwah, NJ: Laurence Earlbaum Associates, 1999.

GOODSON, Ivor. Currículo, narrativa e o futuro social. Tradução Euriza Caldas Pessanha e Marta Banducci Rahe. Revista Brasileira de Educação, v. 12, n. 35, p. 241-252, maio/ ago. 2007.

GORZ, André. O imaterial: conhecimento, valor e capital. São Paulo: Annablume, 2005.

LÉVI-STRAUSS, Claude. O pensamento selvagem. São Paulo: Companhia Editora Nacional, 1976.

MORIN, Edgar. Sociologia: do microssocial ao macroplanetário. 3. ed. Tradução Maria Gabriela de Bragança e Maria da Conceição Coelho. Lisboa: Publicações Europa-américa, 1998.

O método 1: a natureza da natureza. 2. ed. Tradução llana Eindenberg. Porto Alegre: Sulina, 2008.

OLIVEIRA, Marta Khol. Vygotsky. In: Piaget, Vygotsky, Wallon: teorias psicogenéticas em discussão. São Paulo: Summus, 1992.

PATTO, Maria Helena Souza. $\bigcirc$ fracasso escolar como objeto de estudo: anotações sobre as características de um discurso. Cadernos de Pesquisa, São Paulo, n. 65, p. 72-77, maio 1988. 
PIAGET, Jean. Epistemologia genética. 3. ed. Tradução Álvaro Cabral. São Paulo: Martins Fontes, 2007.

SETTON, Maria da Graça Jacinto. A teoria do habitus em Pierre Bourdieu: uma leitura contemporânea. Revista Brasileira de Educação, Rio de Janeiro, n. 20, p. 60-70, maio/ago. 2002.

VARELA, Francisco; THOMPSON, Evan; ROSCH, Eleonor. Embodied mind: cognitive science and human experience. New York: MIT Press, 1993.

VOSS, Rita Ribeiro. Cognição e valores: dois aspectos da educação. Ciências \& Cognição, Rio de Janeiro, v. 14, p. 255-264, mar. 2009.

Dra. Rita Ribeiro Voss

Universidade Federal de Pernambuco Departamento de Fundamentos Sóciofilosóficos da Educação Programa de Pós-Graduação em Educação Líder do Grupo de Pesquisa NARRAEDUC | Narrativas e Educação E-mail | ritavoss@live.com

Recebido 20 maio 2014 Aceito 11 jun. 2014 